\title{
STUDI TEKNIS PENGEMBANGAN JARINGAN BARU DISTIBUSI 20 KV PENYULANG CARGILL DI GARDU INDUK MANYAR
}

\author{
Dwi Aries Sandy (09.632.006) \\ Jurusan Teknik Elektro Fakultas Teknik \\ Universitas Muhammadiyah Gresik \\ Jl. Sumatra 101 GKB(Gresik Kota Baru), Randu Agung, Gresik 61121 Jawa Timur, Indonesia \\ E-mail : shirosandy89@gmail.com
}

\begin{abstract}
Abstrak
Energi listrik sebagai salah satu infrastruktur yang menyangkut hajat hidup orang banyak. Pengembangan sistem distribusi energi listrik merupakan bagian yang esensial dalam mengatasi pertumbuhan kebutuhan energi listrik yang cukup pesat. Salah satu faktor yang mempengaruhi pengembangan jaringan distribusi baru adalah sistem proteksinya.

Penelitian ini bertujuan untuk menghitung arus hubung singkat dan menetukan seting peralatan proteksi serta melakukan perbandingan hasil perhitungan dengan seting yang sudah terpasang di lapangan. Metode yang digunakan dalam penelitian ini adalah metode kuantitatif dengan melakukan pengambilan data secara langsung terhadap objek penelitian pada penyulang Cargill $20 \mathrm{kV}$ di Gardu Induk Manyar yang memiliki arus hubung singkat Gardu Induk sebesar 18,45366 kA per periode januari sampai desember tahun 2015.

Hasil perhitungan memperlihatkan bahwa arus gangguan hubung singkat terbesar yaitu 12.455,31 A untuk gangguan 3 fasa, 10.786,62 A untuk gangguan 2 fasa dan 288,38 A untuk gangguan 1 fasa ke tanah. Berdasarkan hasil penelitian dan analisa bisa disimpulkan bahwa validasi seting proteksi antara perhitungan manual dan kondisi di lapangan untuk penyulang Cargill sudah sesuai dan koordinasi sistem pengaman antara penyulang Cargill dengan sisi incoming dikatakan baik, karena tidak melebihi standart yang diterapkan oleh PLN.
\end{abstract}

Kata kunci : hubung singkat, relai proteksi, penyulang $20 \mathrm{kv}$

\section{PENDAHULUAN}

\subsection{Latar Belakang}

Saluran udara tegangan menengah maupun tegangan rendah dengan kawat terbuka (SUTM dan SUTR terbuka) merupakan saluran yang paling rawan terhadap gangguan eksternal, yaitu gangguan yang diakibatkan dari luar sistem. Gangguan karena sentuhan pohon merupakan penyebab gangguan pelayanan distribusi tenaga listrik yang paling banyak dilaporkan diseluruh unit pelayanan PLN sebagai akibat dari banyaknya pohon - pohon yang tumbuh disekitar jaringan SUTM, baik itu milik masyarakat umum maupun Dinas Pertamanan Pemerintah Kota / Daerah .
Untuk mengatasi gangguan tersebut penerapan dan penggunaan peralatan proteksi mempunyai peranan yang sangat penting, sehingga kontinuitas pelayanan tidak terganggu dalam waktu yang lama.

Tujuan penyusunan makalah ini adalah untuk menghitung besar arus gangguan hubung singkat pada penyulang $20 \mathrm{kv}$ Cargill di Gardu Induk Manyar dengan panjang jaringan $1,768 \mathrm{~km}$. Kemudian menentukan setting untuk relai OCR dan GFR serta membandingkannya dengan setting yang terpasang di lapangan. 


\subsection{Rumusan Masalah}

1. Bagaimana perhitungan arus gangguan hubung singkat pada jaringan $20 \mathrm{kv}$ di PT. PLN (Persero) ?

2. Bagaimana menentukan kapasitas circuit breaker dan penetapan seting proteksi penyulang baru "CARGILL"?

\subsection{Tujuan Penelitian}

1. Menghitung arus gangguan hubung singkat pada jaringan $20 \mathrm{kv}$ mulai dari impedansi sumber di bus sampai impedansi di tiap section jaringannya.

2. Menentukan kapasitas Circuit Breaker yang akan dipasang sebagai media pemutus, bila terjadi gangguan diatas rating yang diijinkan di jaringan distribusi $20 \mathrm{kv}$. Serta penentuan seting sistem proteksi baik OCR (Over Current Relay) yaitu pengaman beban lebih akibat gangguan antar fasa maupun GFR (Ground Fault Relay) yaitu pengaman beban lebih akibat gangguan fasa dengan tanah.

\section{TINJAUAN PUSTAKA}

\subsection{Perhitungan Gangguan Hubung Singkat}

Perhitungan hubung singkat adalah suatu analisa kelakuan sistem tenaga listrik pada keadaan gangguan hubung singkat, dimana dengan cara ini diperoleh nilai besaran - besaran listrik yang dihasilkan sebagai akibat gangguan hubung singkat tersebut. Analisa gangguan hubung singkat diperlukan untuk mempelajari sistem tenaga listrik baik waktu perencanaan maupun setelah beroperasi kelak.[1]

Relai adalah suatu alat pengaman yang bekerja secara otomatis mengukur / memasukkan rangkaian listrik ( rangkaian trip atau alarm ) akibat adanya perubahan rangkain lain. Fungsi sistem pengaman adalah untuk menghindari atau mengurangi kerusakan akibat gangguan pada yang terganggu atau peralatan yang dilalui oleh arus gangguan sehingga dapat memberikan pelayanan listrik dengan keandalan yang tinggi kepada konsumen. [6]
Dengan perhitungan arus gangguan hubung singkat ini dapat digunakan untuk koordinasi relai proteksi arus lebih Over Current Relay (OCR) dari jenis Inverse, manfaatnya menjadi amat terasa karena waktu kerja relai dapat diketahui untuk setiap lokasi gangguan. Relai proteksi lain yang berpengaruh adalah relai gangguan tanah Ground Fault Relay (GFR). Relai ini digunakan sebagai pengaman dimana fungsinya nanti adalah untuk membantu relai differensial pada transformator tenaga dalam mengamankan busbar dari gangguan hubung tanah di dalam daerah pengaman busbar.

\subsection{Gangguan Hubung Singkat Tiga Fasa}

Kemungkinan terjadinya gangguan tiga fasa adalah putusnya salah satu kawat fasa yang letaknya paling atas pada transmisi atau distribusi, dengan konfigurasi kawat antar fasanya disusun secara vertikal. Kemungkinan terjadinya memang sangat kecil, tetapi dalam analisanya tetap harus diperhitungkan.[4]

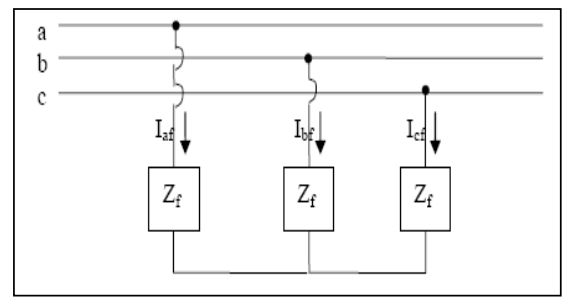

Gambar 1 : Single line diagaram gangguan hubung singkat 3 fasa.

\subsection{Gangguan Hubung Singkat Dua Fasa}

Kemungkinan terjadinya gangguan dua fasa disebabkan oleh putusnya kawat fasa tengah pada transmisi atau distribusi. Kemungkinan lainnya adalah dari rusaknya isolator di transmisi atau distribusi sekaligus 2 fasa. Gangguan seperti ini biasanya mengakibatkan 2 fasa ke tanah.[4]

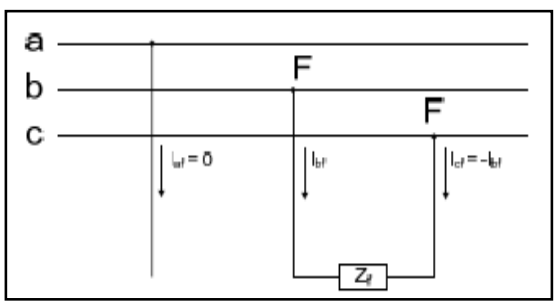

Gambar 2: Single line diagaram gangguan hubung singkat 2 fasa. 


\subsection{Gangguan Hubung Singkat Satu Fasa ke Tanah}

Kemungkinan terjadinya gangguan satu fasa ke tanah adalah back flashover antara tiang ke salah satu kawat transmisi dan distribusi. Sesaat setelah tiang tersambar petir yang besar walaupun tahanan kaki tiangya cukup rendah namun bisa juga gangguan fasa ke tanah ini terjadi sewaktu salah satu kawat fasa transmisi / distribusi tersentuh pohon yang cukup tinggi.[4]

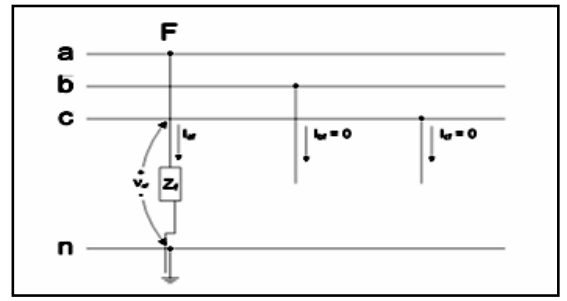

Gambar 3 : Single line diagaram gangguan hubung singkat 1 fasa ke tanah

\subsection{Koordinasi Sistem Pengaman OCR dan GFR}

Setelan arus dari OCR dihitung berdasarkan arus beban yang mengalir di penyulang atau incoming Trafo, artinya untuk OCR yang terpasang di penyulang dihitung berdasarkan arus beban maksimum yang mengalir di penyulang tersebut sedangkan untuk OCR yang terpasang di Incoming Trafo dihitung berdasarkan arus nominal trafo tersebut.

Persyaratan lain yang harus dipenuhi adalah penyetelan waktu minimum dari relai arus lebih ( terutama di penyulang ) tidak lebih kecil dari 0,3 detik. Pertimbangan ini diambil agar relai tidak sampai trip lagi, akibat arus Inrush current dari transformator distribusi yang memang sudah tersambung di jaringan distribusi, sewaktu PMT penyulang tersebut di operasikan. [5]

Penyetelan Ground Fault Relay (GFR) dapat di setel mulai $6 \%$ s/d $12 \% \mathrm{x}$ arus gangguan hubung singkat 1 fasa terjauh/terkecil. Nilai ini untuk mengantisipasi jika penghantar tersentuh pohon, dimana tahanan pohon besar yang dapat memperkecil besarnya arus gangguan hubung singkat 1 fasa ketanah.

\subsection{Penyetelan Time Multiple Setting ( TMS )}

Setelan Time multiple setting (Tms) dan setelan waktu relai pada jaringan distribusi mempergunakan standard Invers, yang dihitung mempergunakan rumus kurva waktu berbanding terbalik dengan arus, dalam hal ini juga diambil persamaan kurva arus waktu dari standard British. karakteristik relai standart invers dapat dilihat pada gambar 4 berikut :[5]

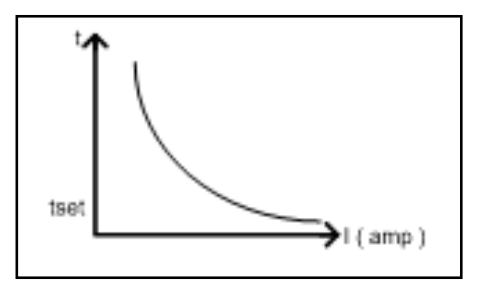

Gambar 4 : Karakteristik relai Standart Invers

\section{METODE PENELITIAN}

\subsection{Studi Literatur}

Mengumpulkan referensi yang menyangkut materi Analisa sistem tenaga listrik baik dari buku, catatan maupun jurnal dari internet mengenai analisis arus hubung singkat secara global maupun perhitungan yang terperinci pada jaringan distribusi di PLN.

\subsection{Pengumpulan Data}

Pengumpulkan data dilakukan di PT. PLN (Persero) Transmisi APP Surabaya dan Distribusi Area Gresik sehingga didapatkan nilai-nilai yang diperlukan sebagai bahan analisa selanjutnya.

\subsection{Perhitungan dan Analisa}

Perhitungan ini dilakukan dengan tujuan untuk mendapatkan nilai besaran yang diperlukan dalam setting peralatan proteksi yang kemudian akan dibandingkan dengan keadaan di lapangan.

\section{a. Impedansi Sumber}

Impedansi di bus $150 \mathrm{kV}$ diperoleh dengan persamaan :

$$
\mathrm{X}_{\mathrm{SC}}=\frac{\mathrm{kV}^{2}}{\mathrm{MVA}}
$$

Konversikan impedansi sumber di bus $150 \mathrm{Kv}$ ke sisi $20 \mathrm{kV}$, dengan persamaan sebagai berikut: 
$\mathrm{X}_{\mathrm{sc}}($ sisi $20 \mathrm{kv})=20^{2} / 150^{2} \mathrm{x} \mathrm{X}_{\mathrm{sc}}($ sisi $150 \mathrm{kV})$

b. Impedansi Trafo tenaga

Dapat dihitung dengan persamaan :

Reaktansi transformator $\left(\mathrm{X}_{\mathrm{T}}\right)=\operatorname{Impedansi}(\%) \mathrm{x}$ (Tegangan sekunder² / Daya )

\section{c. Impedansi Penyulang}

Besarnya impedansi penyulang merupakan total impedansi ohm $/ \mathrm{km}$ dari berbagai jenis penghantar yang digunakan pada jaringan penyulang tersebut.

\section{d. Perhitungan Arus Hubung Singkat}

Perhitungan ini menggunakan persamaan :

Hubung singkat 3 fasa:

If 3 fasa $=\frac{V \text { fasa }- \text { netral }}{\text { Z1 eq }}$

Hubung singkat 2 fasa :

If 2 fasa $=\frac{V \text { fasa }- \text { fasa }}{(\mathrm{Z} 1+\mathrm{Z} 2) \mathrm{eq}}$

Hubung singkat 1 fasa ketanah :

If 1 fasa $=\frac{3 x V \text { fasa }- \text { netral }}{(Z 1+Z 2+Z 0) e q}$

\section{d. Perhitungan Setelan Relai dan TMS}

Dengan persamaan sebagai berikut :

$\operatorname{Tms}=\frac{\operatorname{tx}\left(\left(\frac{\text { I fault }}{\text { I seting }}\right) 0,02-1\right)}{0,14}$

Dan ,

$\mathrm{t}=\frac{\text { Tms } \times 0,14}{\left(\left(\frac{\text { I fault }}{\text { I seting }}\right) \quad 0,02-1\right)}$

\section{e. Pemeriksaan Selektifitas Kerja Relai Arus Lebih}

Pemeriksaan ini dilakukan karena setelan waktu (Tms) pada relai arus lebih jenis inverse bukan menunjukan lamanya waktu kerja relai tersebut. Lamanya waktu kerja relai ini ditentukan oleh besarnya arus gangguan yang mengalir di relai. Makin besar arus gangguan hubung singkat yang mengalir di relai makin cepat kerja relai tersebut menutup kontaknya, kemudian memberikan tripping PMT.

\section{f. Validasi pemakaian CB (Circuit Breaker) pada penyulang Cargill}

Dengan mengetahui besarnya arus gangguan pada transformator, maka dapat menentukan berapa besar ketahanan breakdown peralatan circuit breaker yang harus dipasang. Peralatan main switch yang dipasang harus memiliki ketahanan arus lebih besar dari arus hubung singkat terbesar pada jaringan tersebut.

\section{g. Perbandingan Perhitungan Manual dengan Program MATLAB R2110b}

Sebagai tambahan ilmu dan referensi, penulis juga menambahkan simulasi program menggunkan Matlab R2110b dalam perhitungan ini. Listing program yang terlampir dibuat sesederhana mungkin untuk memudahkan pembaca memahami dan membandingkan hasil perhitungan arus hubung singkat maupun seting pada OCR dan GFR antara penyulang Cargill dan Incoming feeder.

\section{PEMBAHASAN DAN ANALISA}

\subsection{Perhitungan Gangguan Hubung Singkat}

Besar arus gangguan hubung singkat ini dihitung berdasarkan panjang penyulang yang diasumsikan gangguan terjadi pada $1 \%, 5 \%, 10 \%$, $20 \%, 30 \%$ sampai $100 \%$ untuk setiap daerah dari panjang saluran seperti pada gambar berikut :

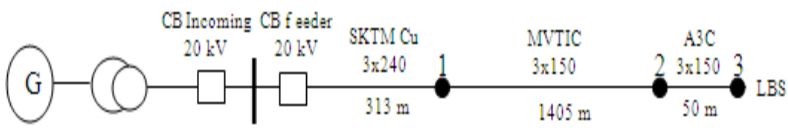

Gambar 5 : Konfigurasi penyulang Cargill

a. Perhitungan impedansi sumber

MVA Hs = arus HS GI Manyar $\mathrm{x}$ tegangan

primer trafo $\mathrm{x} \sqrt{ } 3$

$$
\begin{aligned}
& =18,4536 \mathrm{kA} \times 150 \times \sqrt{ } 3 \\
& =4.794,4 \mathrm{MVA}
\end{aligned}
$$

Impedansi sumber

$$
\begin{aligned}
\left(\mathrm{X}_{\mathrm{sc}}\right) & =\mathrm{kV}^{2} \times \text { MVA Hs } \\
& =150^{2} \times 4.794,4=4,69 \Omega
\end{aligned}
$$

Konversi pada sisi $20 \mathrm{kV}$

$$
\begin{aligned}
\left(\mathrm{X}_{\mathrm{sc}} 20 \mathrm{kV}\right) & =\mathrm{kVS}^{2} / \mathrm{kVP}^{2} \times \mathrm{X}_{\mathrm{sc}} \\
& =20^{2} / 150^{2} \times 4,69=0,08 \Omega
\end{aligned}
$$




\section{b. Perhitungan reaktansi trafo}

Transformator di GI Manyar memiliki daya 60 MVA dengan impedansi 12,5\% dan belitan Yy $\Delta$ plus NGR dengan hambatan dalam sebesar $40 \mathrm{ohm}$, maka :

Reaktansi trafo $\left(\mathrm{X}_{\mathrm{t}}\right)=$ Impedansi $\mathrm{x}($ teg sekunder $^{2} /$ daya )

$\left(X_{t}\right)=12,5 \% \times\left(20^{2} / 60\right)=0,83 \Omega$

$\left(X_{t 0}\right)=3 \times X_{t}=3 \times 0,83=2,499 \Omega$

c. Perhitungan impedansi jaringan

Tabel 1. Data penghantar penyulang Cargill

\begin{tabular}{|c|c|c|c|c|c|}
\hline \multicolumn{2}{|c|}{ DATA PENGHANTAR JARINGAN 20 KV P. CARGILL } \\
\hline $\begin{array}{c}\text { Jenis } \\
\text { Penghantar }\end{array}$ & \multicolumn{2}{|c|}{$\mathbf{Z}_{\mathbf{1}}=\mathbf{Z}_{\mathbf{2}}$} & \multicolumn{2}{|c|}{$\mathbf{Z}_{0}$} & $\begin{array}{c}\text { Jarak } \\
\text { (m) }\end{array}$ \\
\cline { 2 - 5 } & $\mathbf{R}$ & $\mathbf{j} \mathbf{X}$ & $\mathbf{R}$ & j X & \\
\hline SKTM Cu 3x240 & 0,098 & 0,120 & 0,245 & 0,300 & 313 \\
\hline MVTIC 3x150 & 0,265 & 0,130 & 0,663 & 0,325 & 1405 \\
\hline A3C 3x150 & 0,134 & 0,316 & 0,282 & 1,603 & 50 \\
\hline
\end{tabular}

Total impedansi jaringan :

$\mathrm{Z}_{1}=\mathrm{Z}_{2}=(0,098+\mathrm{j} 0,12)+(0,265+\mathrm{j} 0,13)+$

$(0,216+\mathrm{j} 0,33)=(0,579+\mathrm{j} 0,58) \mathrm{ohm} / \mathrm{km}$

$Z_{0}=(0,245+j 0,3)+(0,663+j 0,325)+$

$(0,363+\mathrm{j} 1,618=(1,271+\mathrm{j} 2,243) \mathrm{ohm} / \mathrm{km}$

Impedansi jaringan urutan positif dan negatif persection :

Contoh pada $1 \%$ panjang jaringan,

$1 \%$ x panjang jaringan $\mathrm{x}\left(\mathrm{Z}_{1}=\mathrm{Z}_{2}\right)$

$1 \% \times 1,768 \times(0,579+\mathrm{j} 0,58)=(0,010+\mathrm{j} 0,011) \Omega$ Section selanjutnya menggunakan persamaan yang sama,

Tabel 2. Impedansi jaringan urutan positif dan negatif

\begin{tabular}{|c|c|c|}
\hline No. & \%panjang jaringan $\times$ impedansi total & $Z_{1}=Z_{2}(\mathrm{Ohm})$ \\
\hline 1. & $(1 \% \times 1,768) \times(0,579+\mathrm{j} 0,58)$ & $(0,010+\mathrm{j} 0,011)$ \\
\hline 2. & $(5 \% \times 1,768) \times(0,579+\mathrm{j} 0,58)$ & $(0,051+\mathrm{j} 0,051)$ \\
\hline 3. & $(10 \% \times 1,768) \times(0,579+\mathrm{j} 0,58)$ & $(0,102+\mathrm{j} 0,103)$ \\
\hline 4. & $(20 \% \times 1,768) \times(0,579+\mathrm{j} 0,58)$ & $(0,205+\mathrm{j} 0,205)$ \\
\hline 5. & $(30 \% \times 1,768) \times(0,579+\mathrm{j} 0,58)$ & $(0,307+\mathrm{j} 0,308)$ \\
\hline 6. & $(40 \% \times 1,768) \times(0,579+\mathrm{j} 0,58)$ & $(0,409+\mathrm{j} 0,410)$ \\
\hline 7. & $(50 \% \times 1,768) \times(0,579+\mathrm{j} 0,58)$ & $(0,512+\mathrm{j} 0,513)$ \\
\hline 8. & $(60 \% \times 1,768) \times(0,579+\mathrm{j} 0,58)$ & $(0,614+\mathrm{j} 0,615)$ \\
\hline 9. & $(70 \% \times 1,768) \times(0,579+\mathrm{j} 0,58)$ & $(0,717+\mathrm{j} 0,718)$ \\
\hline 10. & $(80 \% \times 1,768) \times(0,579+\mathrm{j} 0,58)$ & $(0,819+\mathrm{j} 0,820)$ \\
\hline 11. & $(90 \% \times 1,768) \times(0,579+\mathrm{j} 0,58)$ & $(0,921+\mathrm{j} 0,923)$ \\
\hline 12. & $(100 \% \times 1,768) \times(0,579+\mathrm{j} 0,58)$ & $(1,024+\mathrm{j} 1,025)$ \\
\hline
\end{tabular}

Impedansi jaringan urutan nol persection :

Contoh pada $1 \%$ panjang jaringan,

$1 \% \mathrm{x}$ panjang jaringan $\mathrm{x} \mathrm{Z}_{0}$
$1 \% \times 1,768 \times(1,271+\mathrm{j} 2,243)=(0,022+\mathrm{j} 0,040) \Omega$

\begin{tabular}{|c|c|c|c|}
\hline No. & $\%$ panjang & $\mathrm{Z}_{0}+(3 \mathrm{RN}+\mathrm{ZT} 0)$ & $\mathrm{Z}_{0}$ eq $(\mathrm{ohm})$ \\
\hline 1. & $1 \%$ & $(0,022+\mathrm{j} 0,040)+(120+\mathrm{j} 2,499)$ & $(120,022+\mathrm{j} 2,540)$ \\
\hline 2. & $5 \%$ & $(0,112+\mathrm{j} 0,198)+(120+\mathrm{j} 2,499)$ & $(120,112+\mathrm{j} 2,698)$ \\
\hline 3. & $10 \%$ & $(0,225+\mathrm{j} 0,397)+(120+\mathrm{j} 2,499)$ & $(120,225+\mathrm{j} 2,897)$ \\
\hline 4. & $20 \%$ & $(0,449+\mathrm{j} 0,793)+(120+\mathrm{j} 2,499)$ & $(120,449+\mathrm{j} 3,293)$ \\
\hline 5. & $30 \%$ & $(0,674+\mathrm{j} 1,190)+(120+\mathrm{j} 2,499)$ & $(120,674+\mathrm{j} 3,690)$ \\
\hline 6. & $40 \%$ & $(0,899+\mathrm{j} 1,586)+(120+\mathrm{j} 2,499)$ & $(120,899+\mathrm{j} 4,086)$ \\
\hline 7. & $50 \%$ & $(1,124+\mathrm{j} 1,983)+(120+\mathrm{j} 2,499)$ & $(121,124+\mathrm{j} 4,483)$ \\
\hline 8. & $60 \%$ & $(1,348+\mathrm{j} 2,379)+(120+\mathrm{j} 2,499)$ & $(121,348+\mathrm{j} 4,879)$ \\
\hline 9. & $70 \%$ & $(1,573+\mathrm{j} 2,776)+(120+\mathrm{j} 2,499)$ & $(121,573+\mathrm{j} 5,276)$ \\
\hline 10. & $80 \%$ & $(1,798+\mathrm{j} 3,172)+(120+\mathrm{j} 2,499)$ & $(121,798+\mathrm{j} 5,672)$ \\
\hline 11. & $90 \%$ & $(2,022+\mathrm{j} 3,569)+(120+\mathrm{j} 2,499)$ & $(122,022+\mathrm{j} 6,069)$ \\
\hline 12. & $100 \%$ & $(2,247+\mathrm{j} 3,966)+(120+\mathrm{j} 2,499)$ & $(122,247+\mathrm{j} 6,466)$ \\
\hline
\end{tabular}

Section selanjutnya menggunakan persamaan yang sama,

Tabel 3. Impedansi jaringan urutan nol

\begin{tabular}{|c|c|c|c|}
\hline No. & \multicolumn{2}{|c|}{$\%$ panjang jaringan $\mathrm{x}$ impedansi total } & $\mathrm{Z}_{0}(\mathrm{Ohm})$ \\
\hline 1. & \multicolumn{2}{|c|}{$(1 \% \times 1,768) \times(1,271+j 2,243)$} & $(0,022+\mathrm{j} 0,040)$ \\
\hline 2. & \multicolumn{2}{|c|}{$(5 \% \times 1,768) \times(1,271+j 2,243)$} & $(0,112+\mathrm{j} 0,198)$ \\
\hline 3. & \multicolumn{2}{|c|}{$(10 \% \times 1,768) \times(1,271+j 2,243)$} & $(0,225+\mathrm{j} 0,397)$ \\
\hline 4. & \multicolumn{2}{|c|}{$(20 \% \times 1,768) \times(1,271+j 2,243)$} & $(0,449+\mathrm{j} 0,793)$ \\
\hline 5. & \multicolumn{2}{|c|}{$(30 \% \times 1,768) \times(1,271+\mathrm{j} 2,243)$} & $(0,674+\mathrm{j} 1,190)$ \\
\hline 6. & \multicolumn{2}{|c|}{$(40 \% \times 1,768) \times(1,271+\mathrm{j} 2,243)$} & $(0,899+\mathrm{j} 1,586)$ \\
\hline 7. & \multicolumn{2}{|c|}{$(50 \% \times 1,768) \times(1,271+\mathrm{j} 2,243)$} & $(1,124+\mathrm{j} 1,983)$ \\
\hline$\circ$ & \multicolumn{2}{|c|}{$\angle \angle \cap 0 / \ldots 17<0 \backslash \ldots / 1971+: \cap 9 A 2 \backslash$} & $11240+: 12701$ \\
\hline No. & $\%$ Panjang & $\left(Z_{1}=Z_{2}\right)+\left(Z_{S 1}+Z_{T 1}\right)$ ohm & $Z_{1}$ eq $=Z_{2}$ eq $(\mathrm{ohm})$ \\
\hline 1. & $1 \%$ & $(0,010+j 0,011)+(j 0,916)$ & $(0,010+\mathrm{j} 0,927)$ \\
\hline 2. & $5 \%$ & $(0,051+\mathrm{j} 0,051)+(\mathrm{j} 0,916)$ & $(0,051+\mathrm{j} 0,968)$ \\
\hline 3. & $10 \%$ & $(0,102+j 0,103)+(j 0,916)$ & $(0,102+\mathrm{j} 1,019)$ \\
\hline 4. & $20 \%$ & $(0,205+j 0,205)+(j 0,916)$ & $(0,205+\mathrm{j} 1,122)$ \\
\hline 5. & $30 \%$ & $(0,307+j 0,308)+(j 0,916)$ & $(0,307+\mathrm{j} 1,224)$ \\
\hline 6. & $40 \%$ & $(0,409+\mathrm{j} 0,410)+(\mathrm{j} 0,916)$ & $(0,409+\mathrm{j} 1,327)$ \\
\hline 7. & $50 \%$ & $(0,512+j 0,513)+(j 0,916)$ & $(0,512+\mathrm{j} 1,429)$ \\
\hline 8. & $60 \%$ & $(0,614+j 0,615)+(j 0,916)$ & $(0,614+\mathrm{j} 1,532)$ \\
\hline 9. & $70 \%$ & $(0,717+\mathrm{j} 0,718)+(\mathrm{j} 0,916)$ & $(0,717+\mathrm{j} 1,635)$ \\
\hline 10. & $80 \%$ & $(0,819+j 0,820)+(j 0,916)$ & $(0,819+\mathrm{j} 1,737)$ \\
\hline 11. & $90 \%$ & $(0,921+j 0,923)+(j 0,916)$ & $(0,921+\mathrm{j} 1,840)$ \\
\hline 12. & $100 \%$ & $(1,024+j 1,025)+(j 0,916)$ & $(1,024+\mathrm{j} 1,942)$ \\
\hline
\end{tabular}

Perhitungan reaktansi ekivalen urutan positif dan negatif :

Contoh pada $1 \%$ panjang jaringan,

$Z_{1}$ eq $=Z_{2}$ eq $=X_{s c}+X_{t}+\left(Z_{1}=Z_{2}\right)$

$$
\begin{aligned}
& =j 0,083+j 0,83+(0,010+j 0,011) \\
& =(0,010+j 0,927) \Omega
\end{aligned}
$$


Section selanjutnya menggunakan persamaan yang sama,

Tabel 4. Reaktansi ekivalen urutan positif dan negatif

Perhitungan reaktansi ekivalen urutan nol :

Contoh pada $1 \%$ panjang jaringan,

$$
\begin{aligned}
Z_{0} \text { eq } & =3 R N+Z_{t 0}+Z_{0} \\
& =120+j 2,499+(0,022+j 0,040) \\
& =(120,022+j 2,540) \Omega
\end{aligned}
$$

Section selanjutnya menggunakan persamaan yang sama,

Tabel 5. Reaktansi ekivalen urutan nol

\section{d. Perhitungan arus hubung singkat}

Perhitungan besar arus gangguan ini menggunakan persamaan pada bab II dan program bantu Matlab. sehingga didapatkan besar arus gangguan sebagai berikut.

Tabel 6. Besar arus hubung singkat 3 fasa

\begin{tabular}{|c|c|c|}
\hline No. & \% Panjang & $I_{f} 3$ fasa (A) \\
\hline 1. & $1 \%$ & $12.455,31$ \\
\hline 2. & $5 \%$ & $11.911,64$ \\
\hline 3. & $10 \%$ & $11.271,58$ \\
\hline 4. & $20 \%$ & $10.125,57$ \\
\hline 5. & $30 \%$ & $9.147,43$ \\
\hline 6. & $40 \%$ & $8.315,09$ \\
\hline 7. & $50 \%$ & $7.604,95$ \\
\hline 8. & $60 \%$ & $6.995,80$ \\
\hline 9. & $70 \%$ & $6.469,85$ \\
\hline 10. & $80 \%$ & $6.012,57$ \\
\hline 11. & $90 \%$ & $5.612,26$ \\
\hline 12. & $100 \%$ & $5.259,48$ \\
\hline
\end{tabular}

Tabel 7. Besar arus hubung singkat 2 fasa

\begin{tabular}{|c|c|c|}
\hline No. & $\%$ Panjang & If 2 fasa (A) \\
\hline 1. & $1 \%$ & $10.786,62$ \\
\hline 2. & $5 \%$ & $10.315,79$ \\
\hline 3. & $10 \%$ & $9.761,47$ \\
\hline 4. & $20 \%$ & $8.769,00$ \\
\hline 5. & $30 \%$ & $7.921,91$ \\
\hline 6. & $40 \%$ & $7.201,08$ \\
\hline 7. & $50 \%$ & $6.586,08$ \\
\hline 8. & $60 \%$ & $6.058,54$ \\
\hline 9. & $70 \%$ & $5.603,06$ \\
\hline 10. & $80 \%$ & $5.207,04$ \\
\hline 11. & $90 \%$ & $4.860,36$ \\
\hline 12. & $100 \%$ & $4.554,85$ \\
\hline
\end{tabular}

Tabel 8. Besar arus hubung singkat 1 fasa ke tanah

\begin{tabular}{|c|c|c|}
\hline No. & $\%$ Panjang & $I_{f} 1$ fasa (A) \\
\hline 1. & $1 \%$ & 288,38 \\
\hline 2. & $5 \%$ & 287,95 \\
\hline 3. & $10 \%$ & 287,40 \\
\hline 4. & $20 \%$ & 286,32 \\
\hline 5. & $30 \%$ & 285,24 \\
\hline 6. & $40 \%$ & 284,17 \\
\hline 7. & $50 \%$ & 283,09 \\
\hline 8. & $60 \%$ & 282,02 \\
\hline 9. & $70 \%$ & 280,94 \\
\hline 10. & $80 \%$ & 279,87 \\
\hline 11. & $90 \%$ & 278,81 \\
\hline 12. & $100 \%$ & 277,74 \\
\hline
\end{tabular}

\section{e. Perhitungan Setelan Relai OCR dan TMS}

Kapasitas trafo tenaga di GI Manyar 60 MVA dengan Tegangan kerja $150 / 20 \mathrm{kV}$ dan Impedansi sebesar 12,5\%. Menggunakan trafo arus ratio 2.000/5, maka :

$I_{\text {nominal }}=\frac{\text { Kapasitas Trafo }}{(\text { Tegangan sekunder } \mathrm{x} \sqrt{3})}$

$I_{\text {nominal }}=\frac{60.000}{(20 \times 1,7321)}=1.732,1 \mathrm{~A}$

$\mathrm{I}_{\text {seting primer }}=1,05 \times 1.732,1 \mathrm{~A}=1.818,65 \mathrm{~A}$

I seting sekunder $=I_{\text {seting primer }} \times \frac{1}{\text { ratio } C T}$

I seting sekunder $=1.818,65 \times \frac{5}{2.000}=4,55 \mathrm{~A}$

Sedangkan Penyulang Cargill memiliki arus beban nominal sebesar $400 \mathrm{~A}$, dan ratio trafo arusnya adalah 800/5 serta relai arus lebih yang digunakan adalah jenis normal (standard inverse), maka : 
$\mathrm{I}_{\text {seting primer } \quad=1,05 \times \mathrm{I} \text { beban }}$

$$
=1,05 \times 400 \mathrm{~A}=420 \mathrm{~A}
$$

$\mathrm{I}_{\text {seting sekunder }}=\mathrm{I}_{\text {seting primer }} \mathrm{x} \frac{1}{\text { ratio } C T}$

$\mathrm{I}_{\text {seting sekunder }}=420 \times \frac{5}{800}=2,63 \mathrm{~A}$

\section{Perhitungan Setelan Time Multiple Setting}

\section{(TMS)}

sisi Incoming :

$\mathrm{Tms}=\frac{\mathrm{tx}\left(\left(\frac{\mathrm{I} \text { fault }}{\text { I seting primer }}\right)^{\mathrm{k}}-1\right)}{0,14}$

$\operatorname{Tms}=\frac{(0,3+0,4) \times\left(\left(\frac{12.455,31}{1.818,65}\right)^{0,02}-1\right)}{0,14}=0,196$

Sisi Penyulang Cargill :

$\operatorname{Tms}=\frac{\mathrm{tx}\left(\left(\frac{\mathrm{I} \text { fault }}{\text { I seting primer }}\right)^{\mathrm{k}}-1\right)}{0,14}$

$\operatorname{Tms}=\frac{0,3 \times\left(\left(\frac{12.455,31}{420}\right)^{0,02}-1\right)}{0,14}=0,15$

\section{f. Perhitungan Setelan Relai GFR dan TMS}

sisi Incoming :

If $_{\mathrm{f}}$ fasa $=277,74 \mathrm{~A}$

$\mathrm{I}_{\text {seting primer }}=6 \% \times 277,74 \mathrm{~A}=16,66 \mathrm{~A}$

$\mathrm{I}_{\text {seting sekunder }}=16,66 \times 1 /$ ratio $\mathrm{CT}$

$\mathrm{I}_{\text {seting sekunder }}=16,66 \times(5 / 2.000)=0,104 \mathrm{~A}$

Sisi penyulang Cargill :

$\mathrm{I}_{\text {seting primer }}=12 \% \times \mathrm{I}_{\mathrm{f}} 1$ fasa

$\mathrm{I}_{\text {seting primer }}=0,12 \times 277,74 \mathrm{~A}=33,33 \mathrm{~A}$

$\mathrm{I}_{\text {seting sekunder }}=\mathrm{I}_{\text {seting primer } \mathrm{x}} 1 /$ ratio $\mathrm{CT}$

$\mathrm{I}_{\text {seting sekunder }}=33,33 \times(5 / 800)=0,21 \mathrm{~A}$

\section{Perhitungan Setelan Time Multiple Setting (TMS)}

Sisi Incoming :

$\operatorname{Tms}=\frac{\mathrm{tx}\left(\left(\frac{\text { I fault } 1 \text { fasa }}{\text { I seting primer }}\right)^{\mathrm{k}}-1\right)}{0,14}$
$\operatorname{Tms}=\frac{(0,3+0,4) \times\left(\left(\frac{\mathrm{I} 277,74}{16,66}\right)^{\mathrm{k}}-1\right)}{0,14}=0,289$

Sisi Penyulang Cargill :

$\mathrm{Tms}=\frac{\mathrm{tx}\left(\left(\frac{\text { I fault } 1 \text { fasa }}{\text { I seting primer }}\right)^{\mathrm{k}}-1\right)}{0,14}$

$\operatorname{Tms}=\frac{0,3 \times\left(\left(\frac{277,74}{33,33}\right)^{0,02}-1\right)}{0,14}=0,093$

\section{g. Validasi pemakaian CB (Circuit Breaker) pada penyulang Cargill}

Dengan mengetahui besarnya arus gangguan pada transformator, maka dapat menentukan berapa besar ketahanan breakdown peralatan circuit Breaker yang harus dipasang. Peralatan main switch yang dipasang harus memiliki ketahanan arus lebih besar dari arus hubung singkat terbesar pada jaringan tersebut 12.455,31 A. Hal itu sudah sesuai kondisi dilapangan, karena penyulang Cargill sudah menggunakan CB dengan kapasitas $25 \mathrm{kA}$.

\section{h. Validasi seting proteksi dengan data di lapangan}

Tabel 9. Perbandingan Seting OCR antara perhitungan manual, perhitungan matlab dan data di lapangan

\begin{tabular}{|c|c|c|c|}
\hline \multicolumn{4}{|c|}{ OCR (Over current Relay) } \\
\hline Penyulang Cargill & $\begin{array}{c}\text { Perhitungan } \\
\text { Manual }\end{array}$ & $\begin{array}{c}\text { Perhitungan } \\
\text { Matlab }\end{array}$ & $\begin{array}{c}\text { Data } \\
\text { lapangan }\end{array}$ \\
\hline Tms (SI) & 0,15 & 0,15031 & 0,15 \\
\hline $\mathrm{t}$ (detik) & 0,3 & 0,3 & 0,3 \\
\hline Incoming feeder & \multicolumn{3}{|}{} \\
\hline Tms (SI) & 0,20 & 0,19616 & 0,20 \\
\hline $\mathrm{t}$ (detik) & 0,7 & 0,7 & 0,7 \\
\hline
\end{tabular}

Tabel 10. Perbandingan Seting GFR antara perhitungan manual, perhitungan matlab dan data di

\begin{tabular}{|c|c|c|c|}
\hline \multicolumn{4}{|c|}{ GFR (Ground fault Relay) } \\
\hline Penyulang Cargill & $\begin{array}{c}\text { Perhitungan } \\
\text { Manual }\end{array}$ & $\begin{array}{c}\text { Perhitungan } \\
\text { Matlab }\end{array}$ & $\begin{array}{c}\text { Data } \\
\text { lapangan }\end{array}$ \\
\hline Tms (SI) & 0,093 & 0,092823 & 0,1 \\
\hline $\mathrm{t}$ (detik) & 0,3 & 0,3 & 0,3 \\
\hline Incoming feeder & \multicolumn{3}{|}{} \\
\hline Tms (SI) & 0,289 & 0,28941 & 0,3 \\
\hline $\mathrm{t}$ (detik) & 0,7 & 0,7 & 0,7 \\
\hline
\end{tabular}

\section{PENUTUP}




\subsection{Kesimpulan}

Arus gangguan hubung singkat 3 fasa pada penyulang Cargill di GI Manyar dengan total impedansi jaringan penyulang urutan positif $(0,579+\mathrm{j}$ $0,58) \mathrm{ohm} / \mathrm{km}$ dan impedansi jaringan urutan nol sebesar $(1,271+\mathrm{j} 2,243) \mathrm{ohm} / \mathrm{km}$ yang memiliki panjang jaringan $1,768 \mathrm{~km}$ adalah sebesar $12.455,31 \mathrm{~A}$ dan sebesar 10.786,62 untuk arus gangguan 2 fasanya. Sedangkan arus gangguan 1 fasa ke tanah sebesar 288,38 A. Dengan koordinasi seting proteksi 0,15 SI untuk penyulang Cargill dan 0,20 SI untuk sisi Incoming dengan waktu 0,3 detik untuk penyulang Cargill dan 0,7 detik untuk sisi Incoming pada relai OCR. Sedangkan pada relai GFR 0,09 SI untuk penyulang Cargill dan 0,29 SI untuk sisi Incoming dengan waktu 0,3 detik untuk penyulang Cargill dan 0,7 detik untuk sisi Incomingnya.

Circuit Breaker yang terpasang pada penyulang Cargill adalah 25 kA. Dengan demikian membuktikan bahwa kapasitas Circuit Breaker yang terpasang sudah melebihi arus hubung singkat terbesar pada jaringan tersebut, yaitu 12,45531 kA.

Berdasarkan hasil penelitian dan analisa dapat disimpulkan bahwa validasi seting proteksi antara perhitungan manual dan kondisi di lapangan untuk penyulang Cargill sudah sesuai dan koordinasi sistem pengaman antara penyulang Cargill dengan sisi incoming dikatakan baik, karena tidak melebihi standart dari PLN, yaitu dengan selisih 0,5 SI untuk seting TMS dan 0,3 detik untuk seting waktu pada relai OCR dan GFR.

\subsection{Saran}

1. Perlu adanya pengecekan secara berkala pada peralatan proteksi yang terpasang di jaringan untuk menghindari kegagalan operasi pada sistem proteksi bila terjadi gangguan, mengingat pasokan tenaga listrik ke konsumen sangat penting sehingga daerah pemadaman tidak menjadi lebih luas.

2. Pemangkasan dahan pohon yang berada dibawah atau sekitar jaringan penyulang Cargill yang berpotensi dapat menyebabkan gangguan karena jaringan pada penyulang ini bersifat Radial.

\section{DAFTAR PUSTAKA}

1. Gonen, Turan, Electric Power Distribution System Engineering, McGraw-Hill, Singapore, 1986

2. Zuhal, Dasar Teknik Tenaga Listrik dan Elektronika Daya, Gramedia, Jakarta, 1988

3. Weedy, B.M, Sistem Tenaga Listrik, Edisi ke-3, Aksara Persada, Jakarta, 1988

4. SPLN 59, Keandalan Pada Sistem Distribusi 20 kV dan 6 kV, 1985

5. SPLN 68, Penentuan Seting Sistem Distribusi 20 kV , 1990

6. Perusahaan Umum Listrik Negara, SPLN 52-3 :1983, Pola Pengamanan Sistem, Departemen Pertambangan dan Energi, Jakarta, 1983

7. Gonen, Turan, Electrical Power Transmission System Engineering Analysis and Design, John Wiley \& Sons Inc, USA, 1988

8. Stevenson Jr,W.D, Analisa Sistem Tenaga Listrik, Erlangga, Jakarta, 1996

\section{BIODATA}

Penulis bernama lengkap DWI ARIES SANDY, lahir di Gresik Propinsi Jawa Timur pada tanggal 29 Juni 1989, merupakan anak kedua dari dua bersaudara. Penulis lahir dari pasangan suami istri Bapak Wagiono dan Ibu Musri'ah. Penulis sekarang bertempat tinggal di Jalan Kapten Darmo Sugondo No.3 desa Karang - Kering. Dengan riwayat pendidikan di SDN Karang - Kering Gresik lulus tahun 2001, SMPN 3 Gresik lulus tahun 2004 , SMK Semen Gresik lulus 2007 dan saat ini sedang menjalankan studi strata 1 di Teknik Elektro Fakultas Teknik Universitas Muhammadiyah Gresik

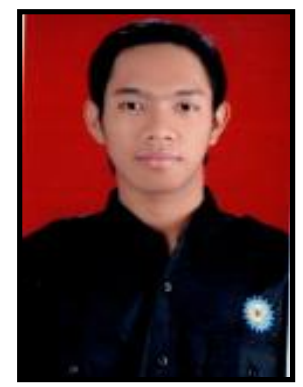

Pembimbing

Penulis

Ir.Hadi Suroso,M.Sc.

Dwi Aries Sandy 